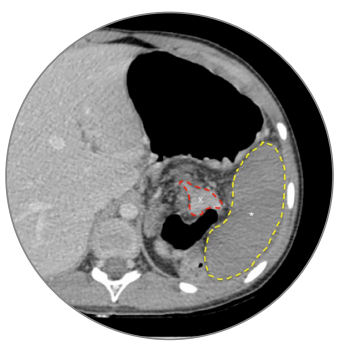

\section{Torsión e infarto esplénico en paciente pediátrico. Presentación de caso}

\author{
Torsion and Splenic Infarction in Pediatric Patient. A Case Report
}

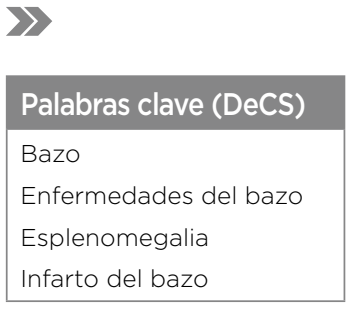

Key words (MeSH)

Spleen

Splenic diseases

Splenomegaly

Splenic infarction
Médica pediatra, Clínica Comfamiliar. Pereira, Colombia.

2Médica general, Universidad Cooperativa de Colombia.

${ }^{3}$ Médico radiólogo, Radiólogos Asociados. Pereira, Colombia.

${ }^{4}$ Médica cirujana pediatra, Clínica Comfamiliar. Pereira, Colombia.

${ }^{5}$ Médica residente de pediatría, Universidad Tecnológica de Pereira. Pereira, Colombia.

\title{
Resumen
}

El bazo errante es una patología poco común, en la cual el bazo se encuentra fuera de su ubicación habitual, como consecuencia de una laxitud anormal o ausencia de ligamentos, lo cual predispone a torsión e infarto; es más frecuente en niños menores de 10 años y en mujeres en la tercera década de la vida. A menudo, los pacientes consultan por una masa abdominal asintomática, o síntomas gastrointestinales subagudos e incluso abdomen agudo. El diagnóstico se realiza mediante imágenes y su manejo es quirúrgico. El caso examinado corresponde a una paciente de sexo femenino de 11 años de edad, diagnosticada con torsión e infarto esplénico mediante ecografía y tomografía axial computarizada (TAC); se realiza manejo quirúrgico sin complicaciones.

\section{Summary}

Wandering spleen is a rare pathology in which the spleen is not in its usual location, secondary to abnormal laxity or absence of ligaments, predisposing to torsion and infarction, more frequent in children under 10 years of age and women in the third decade of life. Patients often consult for an asymptomatic abdominal mass or subacute gastrointestinal symptoms and even acute abdomen. Diagnosis is made through images and its management is surgical. In this case, an 11-year-old female patient is presented, diagnosed with splenic torsion and infarction by computerized axial tomography (CT) and ultrasound. Surgical management is performed without complications.

\section{Introducción}

El bazo errante es una patología infrecuente asociada a complicaciones como la torsión del pedículo vascular e infarto (1). La tasa de incidencia en pacientes sometidos a esplenectomía es del 0,2\% $(2,3)$. La sintomatología generalmente es inespecífica. En los casos pediátricos, la presentación clínica suele incluir náuseas, vómito y fiebre o abdomen agudo (1).

Las imágenes diagnósticas cumplen un papel fundamental en su diagnóstico, e incluyen: bazo en una posición anormal fuera del cuadrante superior izquierdo o con orientación anormal, remolino de las estructuras vasculares del pedículo, trombosis de la vena esplénica, ascitis, esplenomegalia, bajo realce del medio de contraste esplénico y de vasos esplénicos y estriación de la grasa periesplénica $(1,2,4)$. El manejo puede ser expectante con observación clínica o quirúrgico (5).

\section{Caso clínico}

Paciente de 11 años de edad, sexo femenino, con antecedentes patológicos de asma, tuberculosis pulmonar y apendicectomía. Ingresó a la institución por cuadro clínico de 12 horas de dolor abdominal en epigastrio y mesogastrio, náuseas, vómito y ausencia de deposiciones, al examen físico se evidenció dolor a la palpación abdominal, sin signos de irritación peritoneal. Se solicitó estudio ecográfico en el que se identificó el bazo en una localización atípica infrarrenal izquierda, sin otros hallazgos de interés. Se indicó observación y manejo del dolor, con evolución clínica satisfactoria y posterior egreso hospitalario.

Cinco días después, la paciente consulta nuevamente por dolor abdominal de intensidad 10/10 en la escala verbal análoga, localizado en el hipocondrio izquierdo de 6 horas de evolución; al examen físico se evidencia dolor a la palpación en el hipocondrio izquierdo y epigastrio, sin signos de irritación peritoneal. El estudio radiográfico muestra signo de Chilaiditi izquierdo y distensión del colon trasverso y de las asas del intestino delgado. Una nueva ecografía de abdomen evidencia esplenomegalia de 13,8 cm, con el hallazgo notable del bazo situado en una localización convencional (sobre el riñón) y aspecto hipoecoico, líquido interasas en las fosas ilíacas y en la cavidad pélvica, evento que motiva la sospecha de torsión esplénica (figura 1).

Posteriormente, se realizó TAC de abdomen, se encontró el bazo incrementado de tamaño, signo del 


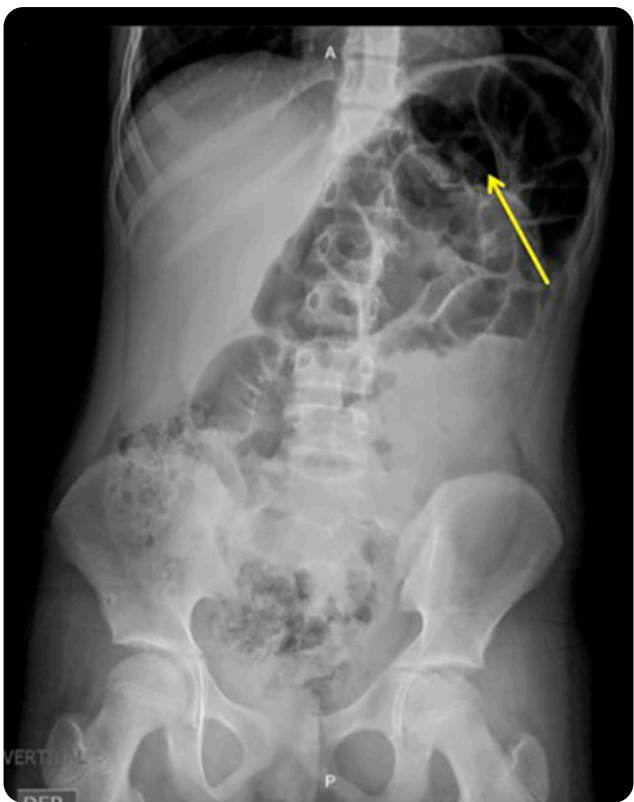

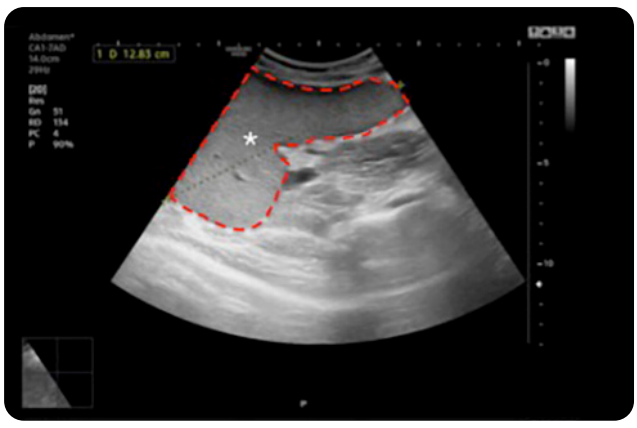

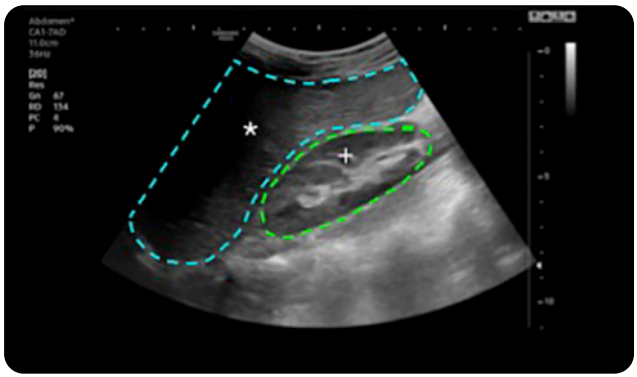

Figura 1. a) RX de abdomen AP: se observa signo de Chilaiditi izquierdo asociado a distensión de asas colónicas y de intestino delgado, no se logra identificar la silueta esplénica ni renal. b) Ecografía inicial, silueta esplénica (*), no se observa el riñón por su ubicación superior. c) Segunda ecografía realizada 5 días después con 6 horas de síntomas, se observa el bazo $\left(^{*}\right)$ nótese la ubicación convenciona del riñón (+), es evidente la menor ecogenicidad del bazo en esta imagen al compararla con la previa.

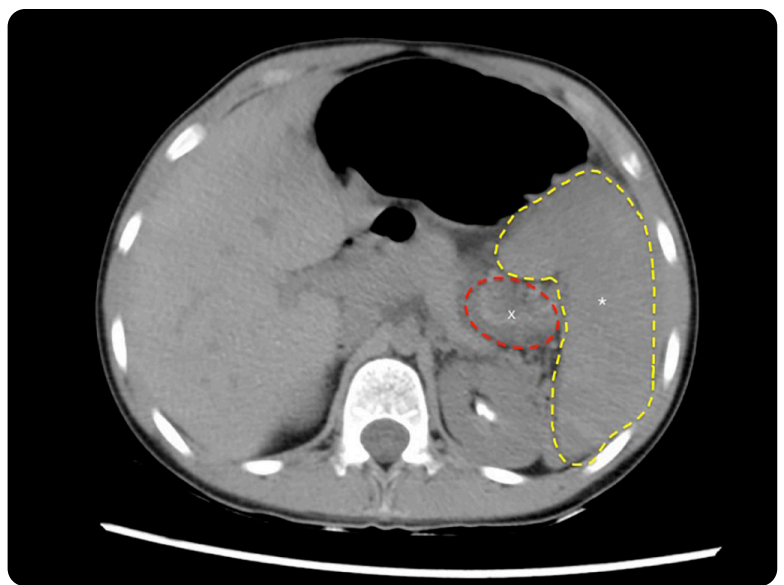

Figura 2. TAC fase simple, se observa el bazo con localización habitual $\left.{ }^{*}\right)$, hipodenso en relación con el hígado, imágenes hiperdensas lineales compatibles con estructuras vasculares trombosadas en el hilio esplénico $(X)$.

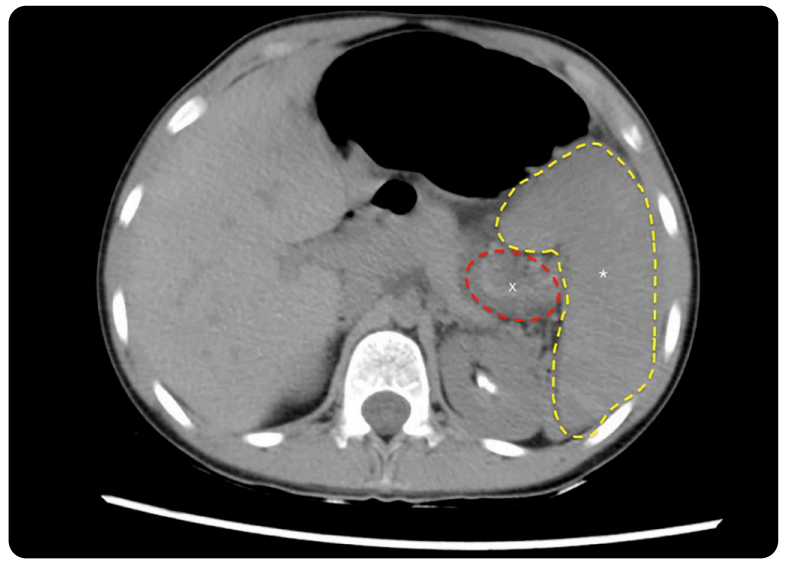

Figura 4. TAC fase portal. Se observa signo del remolino vascular (X), el pedículo vascular y el hilio esplénico persisten sin realce del medio de contraste, al igual que el bazo (*), se menciona la densidad del hígado de $110 \mathrm{UH}$, en comparación con la del bazo de $43 \mathrm{UH}$, con una proporción de densidad hígado-bazo superior a 2.

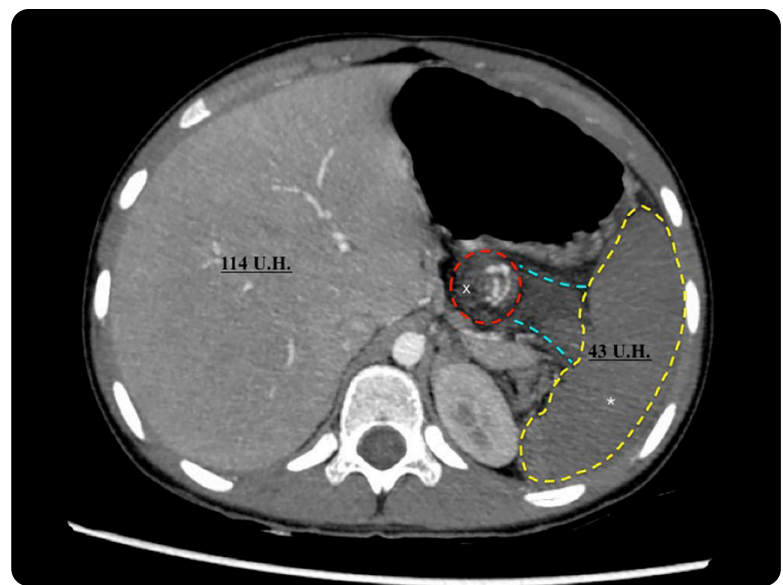

Figura 3. TAC fase arterial. Se observa signo del remolino vascular $(X)$, el pedículo vascular e hilio esplénico sin realce del medio de contraste al igual que el bazo, se menciona la densidad del hígado de $114 \mathrm{UH}$, en comparación con la del bazo de $43 \mathrm{UH}\left({ }^{*}\right)$, con una proporción de densidad hígado-bazo superior a 2.

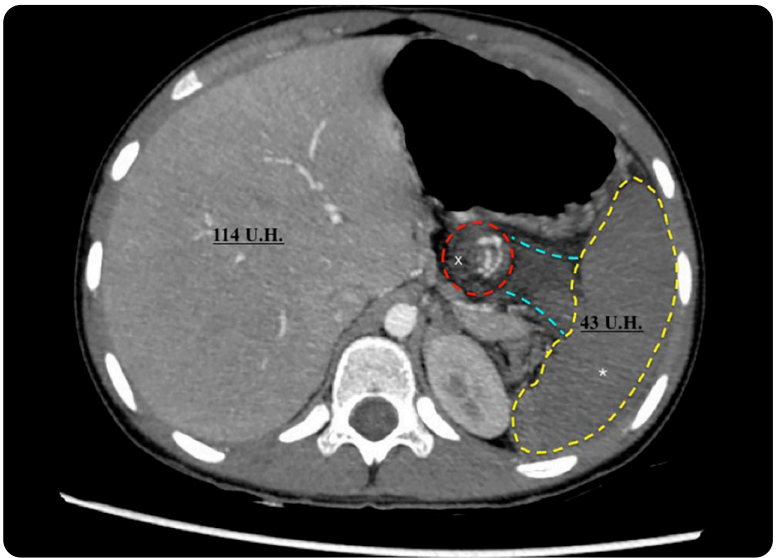

Figura 5. TAC fase portal. Se observa el extremo distal de la cola del páncreas incluido en el foco de la torsión (X), el bazo persiste hipodenso en relación con el hígado. Video de tomografía en el siguiente enlace: https://www. youtube.com/watch?v=4PXeyvWbNvg 

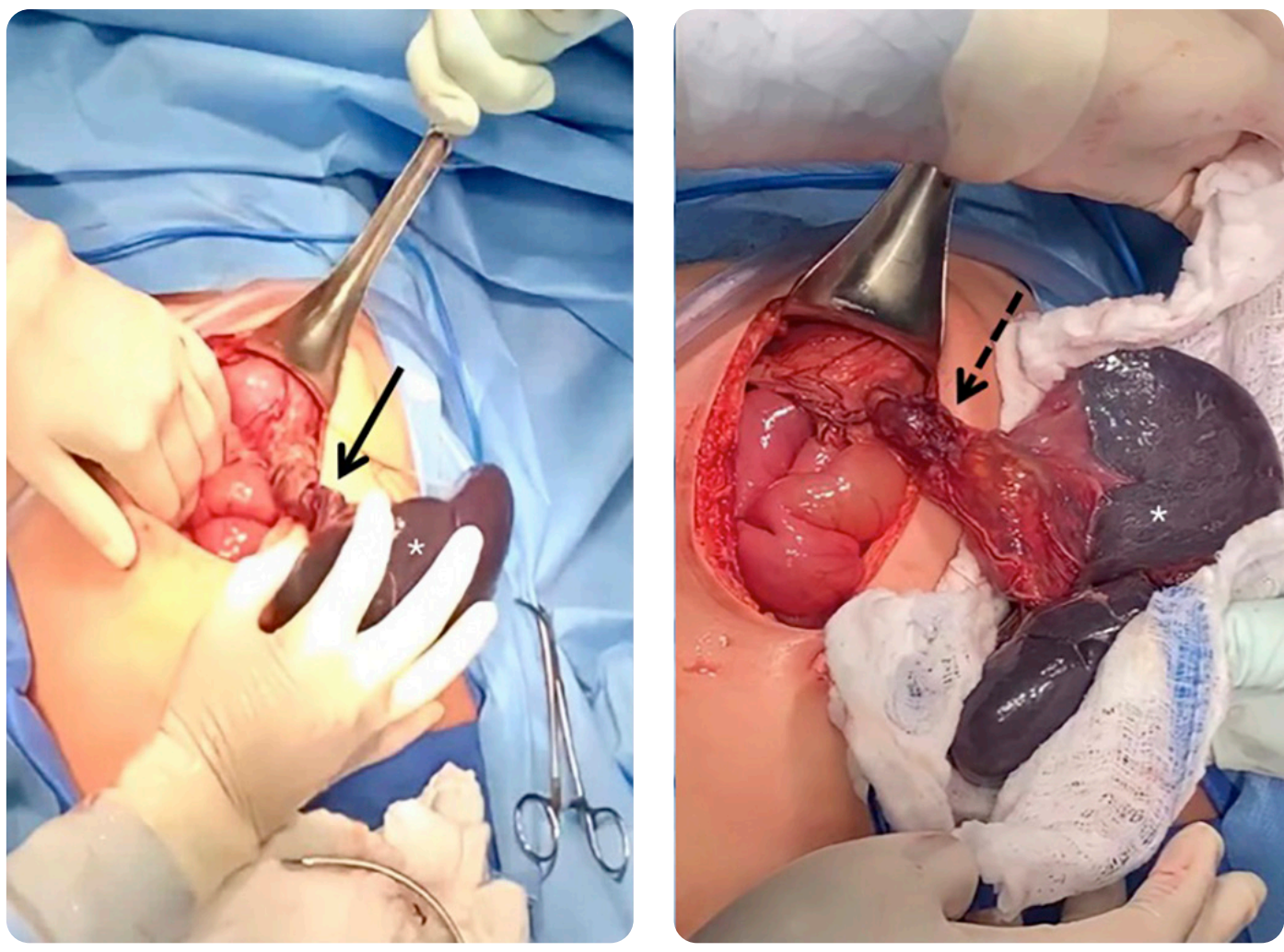

Figura 6. Fotografías de procedimiento quirúrgico. a) Esplenomegalia con signos sugestivos de isquemia con pedículo torsionado (flecha) y ausencia de los ligamentos de fijación del bazo. b) Luego de la detorsión del pedículo marcado con flecha, persisten signos de isquemia.

remolino vascular en el hilio esplénico con torsión que comprometía la cola del páncreas, bazo hipodenso con una densidad de $43 \mathrm{UH}$ en las diferentes fases (simple, arterial, venosa y tardía); no se identificó el realce, se observó hipodenso con respecto al hígado en las diferentes adquisiciones. Durante la fase simple, la densidad del bazo fue de 23 UH — menor que la del hígado — con aumento de la densidad de algunas estructuras vasculares en el hilio esplénico, lo cual sugirió trombosis. En la fase venosa, el hígado alcanzó una densidad de 110 UH para una proporción de densidades hígado/bazo de 2,5. Se diagnosticó torsión esplénica con signos de isquemia (figuras 2,3,4,5) (enlace a imágenes completas https://www.youtube.com/watch?v=4PXeyvWbNvg ).

Se realizó laparotomía de urgencia, con hallazgo de bazo flotante con torsión esplénica de $720^{\circ}$ e infarto esplénico que no se recuperó tras la detorsión, ligamentos de fijación ausentes, trombosis de vasos esplénicos, cola del páncreas también incluida en la torsión sin isquemia (figura 6). Se le practicó esplenectomía sin complicaciones, profilaxis antibiótica por riesgo de sepsis fulminante por gérmenes encapsulados y actualización de esquema de vacunación. Siete días después se le indicó egreso con evolución satisfactoria.

\section{Discusión}

La incidencia del bazo errante es del 0,2\%, y es más común en menores de 10 años y en mujeres en etapa reproductiva; su etiopatogenia aún no es clara y su origen es congénito o adquirido. Entre de los factores de riesgo asociados a torsión esplénica se encuentran: embarazo, esplenomegalia, multiparidad, quistes esplénicos, enfermedad de Hodgkin, malaria, linfangioma, agenesia renal, mononucleosis, enfermedad de Gaucher y síndrome de DiGeorge (1-3,6). Se han descrito pocos casos en pediatría $(1,7,8)$. En cuanto a los diagnósticos diferenciales, se deben incluir: linfoma, crisis de secuestro esplénico, embolismo arterial y trombosis venosa (6). Los pacientes con esta condición pueden ser asintomáticos, presentarse con síntomas gastrointestinales inespecíficos o con abdomen agudo, como en el caso aquí descrito. Al igual que en otras estructuras, puede haber torsión y detorsión, circunstancia que desencadena cuadros de dolor abdominal crónico. En una revisión sistemática, en pacientes adultos con bazo errante tratados con un enfoque quirúrgico, las manifestaciones más comunes fueron dolor abdominal y masa abdominal y, aproximadamente, la mitad de los pacientes tuvieron un inicio clínico agudo (5). La ecografía, el análisis Doppler y la TAC tienen un papel fundamental en el diagnóstico. En este caso, la ecografía inicial mostró un bazo de localización infrarrenal izquierda con un aspecto ecográfico normal y en el estudio ecográfico posterior (realizada al quinto día) se observó un bazo de localización convencional, lo que indicó desplazamiento de esta estructura y sugirió su torsión, la cual se confirmó con TAC, lo que resalta la importancia de la revisión de los estudios imagenológicos previos. Otro signo ecográfico que sugirió la isquemia fue el aspecto hipoecoico, por lo que la comparación de la ecogenicidad de las diferentes estructuras sigue teniendo un rol relevante para el diagnóstico, además de la importancia para el especialista en imágenes diagnósticas de familiarizarse con el aspecto y grado de ecogenicidad que tienen las diferentes estructuras; sin embargo, hay estudios que sugieren un aspecto hiperecoico (1). La TAC con medio de contraste es la mejor herramienta para llegar al diagnóstico, como en el caso presente, en el que se sospechó por ecografía y finalmente se 
confirmó por TAC, logrando identificar algunos signos típicos, como el remolino vascular del hilio esplénico, no realce del medio de contraste en las diferentes fases, lo que sugirió isquemia, e igualmente una densidad inferior a $45 \mathrm{UH}$; además, una proporción de densidades hígado/ bazo superior a 2; signos descritos como sospechosos de isquemia (4). Entre las complicaciones asociadas a torsión, además de infarto, deben tenerse en cuenta asplenia funcional, pancreatitis, obstrucción intestinal o vólvulo gástrico, ruptura esplénica y hemoperitoneo $(1,6)$. En cuanto al manejo, en algunos casos se realizan recomendaciones y observación, tratamiento quirúrgico tradicional con esplenectomía y nuevas técnicas que tienen por objeto la desrotación y la fijación del bazo en una posición anatómica mediante suturas, bolsillos del peritoneo o mallas. En esta paciente, luego de la desrotación persistían signos de isquemia, por lo que se realizó esplenectomía $(4,8)$. Igualmente, es importante la aplicación de profilaxis antibiótica y vacunación por el riesgo aumentado de infecciones por gérmenes encapsulados.

\section{Referencias}

1. Wang Z, Zhao Q, Huang Y, Mo Z, Tian Z, Yang F, et al. Wandering spleen with splenic torsion in a toddler: A case report and literature review. Medicine. 2020;99(37):e22063.

2. Reisner DC, Burgan CM. Wandering Spleen: An overview. Curr Probl Diagn Radiol. 2018;47(1):68-70.

3. Buehner M, Baker MS. The wandering spleen. Surg, Gynecol Obstet. 1992;175(4):373-87.

4. Cetinoglu YK, Karasu S, Acar T, Uluc ME, Haciyanli M, Tosun O. Torsion of wandering spleen: Importance of splenic density and liver-to- spleen attenuation ratio on CT. Curr Med Imag. 2020;16:88.

5. Barabino M, Luigiano C, Pellicano R, Giovenzana M, Santambrogio R, Pisani A, et al. Wandering spleen as a rare cause of recurrent abdominal pain: a systematic review. Minerva Chir. 2019;74(4):359-63.

6. Mohseni M, Kruse BT, Graham C. Splenic torsion: a rare cause of abdominal pain. BMJ Case Rep. 2018;2018:bcr2018224952.

7. Lombardi R, Menchini L, Corneli T, Magistrelli A, Accinni A, Monti L, et al. Wandering spleen in children: a report of 3 cases and a brief literature review underlining the importance of diagnostic imaging. Pediat Radiol. 2014;44(3):279-88.

8. Hui Lian H, Hayati F, Ali AA, Azizan N, Che Ani MF, Suhaili MA, et al. Wandering spleen: a unique cause of acute abdomen. Folia Morphol. 2018;77(2):400-2.

\section{Correspondencia}

Néstor Ramírez Mejía

Carrera 19 \# 9-110

Pereira, Colombia

nestor32co@gmail.com

Recibido para evaluación: 23 de octubre de 2020

Aceptado para publicación: 15 de enero de 2021 